821.111(73).09-31

https://doi.org/10.18485/bells.2021.13.11

\title{
Slađana Stamenković
}

University of Novi Sad

Faculty of Philosophy

Novi Sad, Serbia

\section{HUMAN IDENTITY IN HYPER-REALITY: THE HYPERREAL SELF IN DON DELILLO'S COSMOPOLIS AND THE SILENCE}

\begin{abstract}
In his novels, DeLillo frequently tackles the concept of hyperreality and its effect on human lives, as well as on fundamental concepts of human existence, such as the concept of personal identity. In Cosmopolis and The Silence, the interference of hyperreality propagated by technology and the media in human lives and the quotidian is regarded from different angles. This paper observes how the novels approach this unique interaction parallelly, seemingly offering the same conclusion - that technology and the mass media are the key factors in how people perceive both their environment and self, and in that, how they perceive reality and the world. These elements prove to be essential to the contemporary society of DeLillo's novels.
\end{abstract}

Key words: hyperreality, personal identity, DeLillo, Cosmopolis, The Silence

E-mail address: sladjana.stamenkovic@ff.uns.ac.rs 


\section{Introduction}

One of the main themes of DeLillo's prose that connects Cosmopolis and The Silence is human identity in contemporary society, specifically regarding the media hyperreality that engulfs the American quotidian in DeLillo's novels. Both novels focus on the complex question of human existence in the hightech society, only from different perspectives. Cosmopolis all but boasts the presence of cutting-edge technology, whereas The Silence explores the potential scenario of losing it altogether. At first sight, it seems that the novels focus on the influence of modern technology on American society, but there is also a more complex issue behind the obvious one. Rather than considering it a mere influence, DeLillo discusses the fusion between the human and the mechanical (thus exploring the existence of the socalled homo technologicus) as a central issue of contemporary society. He observes this merger as the "new" reality, which Baudrillard defines as hyperreality (Baudrillard 1994: 22). The term homo technologicus (as seen in Laist 2010, among others) could be defined as a unique representation of a human individual that has come to exist in somewhat of a symbiosis with technology, requiring it for different aspects of life (for example, to facilitate daily activities and chores, to provide information, to help one's positioning in the community one inhabits and other similar aspects of life). As a result, one's perspective of reality becomes modified, as frequently seen in DeLillo's novels (besides the ones that are discussed in this paper, examples of this issue are Zero K, Falling Man, Underworld and Libra, or plays such as Valparaiso). In such a confusing state of reality, the concept of the Self, or personal identity, also becomes thwarted, and the issue of what it means to be human suddenly poses a much more complex and abstract question. This paper analyzes DeLillo's approach to human identity in contemporary society that is a markedly technological dystopia within which the issue of what it means to be human becomes deeply conditioned by the media and technology.

In Cosmopolis, DeLillo's protagonist is Eric Packer, a multi-billionaire on a day-long journey to get a haircut. He is a representative of the "New World Order global elite," as Noble notes (Noble 2010: 58). Arguably, we might call him a contemporary, and much more egoistical, Leopold Bloom or even Odysseus, cruising the New York City in his high-tech limousine, monitoring the flow of the cyber-capital. In this sense, we can discuss this character as DeLillo's means of mythical deconstruction, or more precisely, 
Slađana Stamenković: Human Identity in Hyper-Reality: The Hyperreal Self in Don Delillo's...

the deconstruction of the "negative myths that are created as the means of repression" (Paunović 2017: 178). Packer is a protagonist who seems to be greater than life (as he seems to perceive himself, most notably because of his financial power), but he is also a metaphor, DeLillo's means of "merging the universal and the individual" (Paunović 2017: 181). Packer is also a shell of a man, since he exists almost entirely in the digital world of information, to an extent defined by the hyperreality he inhabits. DeLillo uses him to portray contemporary society's obsession with money and the contemporary incarnation of the American Dream. Moreover, DeLillo uses his protagonist to introduce the question of our changing perception of reality, as well as of what it means to be human in a hyperreal world. Packer is a representative of a typical American citizen (though extremely and even unbelievably rich) that lives a mobile life, constantly blurring the line between the real and the hyperreal. In such circumstances, the question of personal identity becomes elusive. Eric Packer is predominantly defined through his work and the things he owns (gadgets and real estate to the seemingly same extent), but when it comes to him as a person, other than his vague childhood memories that subconsciously dictate his itinerary throughout the day, there is not much at disposal. He is by far more technologicus than homo throughout the novel.

As opposed to Eric, the protagonists of The Silence are each a vivid representative of homo non-technologicus, albeit without their consent, since they are forced into existence without technology by factors outside of their control (in this case, it is a mysterious global failure of media and communication technology). The novel introduces a contemporary catastrophe only imaginable (and feared) by the society of the late 2010s and early 2020s - a world forcedly stripped off of its technological extensions. The Silence begins with a threat of a plane crash, but it is the media and communication technology that crash spectacularly. Left together, yet alone, the protagonists (a group of friends gathered to watch the Superbowl game) try filling the void left by the sudden absence of the media and media content. However, they soon discover that they are in desperate need of both the media and technology in order to function on a daily basis, either as individuals or persons operating within a group. Their communication diminishes and disappears altogether, even between spouses, because they cannot seem to tackle human interaction in any meaningful way without the media to guide their consciousness and conversational topics. Where Cosmopolis highlighted the overwhelming 
presence of technology and the media in people's everyday lives, The Silence dares to imagine the world without either, thus ironically highlighting the importance they have in the contemporary era. The novels flirt with the concept of destruction and potential dystopian society that might emerge from the media engulfed society DeLillo observes. Homo technologicus, it seems, has no hope in avoiding an apocalyptic scenario in the near future of DeLillo's America. The factor that brings about this destiny of homo technologicus is something that contemporary society created itself: hyperreality. This phenomenon is introduced by Jean Baudrillard (Baudrillard 1994: 22) and his theories of simulacra and hyperreality. The concept is discussed as a vital element of the media- and technology-led society of the $21^{\text {st }}$ century in DeLillo's novels. It suggests deeper patterns of behavior that affect human perception of reality and their environment, as well as of their identity.

In the context of DeLillo's earlier novels, both Cosmopolis and The Silence represent a natural development of similar ideas and observations about the society of the late 20th century and its future. His early ideas about technology and the mass media (as something interwoven into Western society and its quotidian) are evident in almost all his novels, most notably in Underworld, White Noise and Ratner's Star. Each of them seems to suggest that the bond between people and technology is an everevolving dependency, leading to people's inability to live a life without the aid of technology. Regarding the mass media in particular, DeLillo has always taken a step further, suggesting, as Duvall notices using the example of television in White Noise, that it "does not stop at structuring the conscious thinking of DeLillo's characters" but indeed influences their entire perception of reality on a subconscious level, as well (Duvall 2008: 176). This is not true only for the Gladneys in White Noise, but also for David Bell in Americana, Lyle and Pammy Wynant in Players, and different members of the Shay family in Underworld, to name a few examples. All of them subconsciously build not only their perception of the world, but also of themselves, as well as of the numerous interpersonal relationships with other people. As Stojmenović notes, DeLillo constantly observes the "effects of media produced [...] representations of the quotidian"1 on the patterns of behavior in everyday human lives, in which she includes representations produced by television, film and advertising, but also literature, popular culture and other critical and theoretical influences (Stojmenović 2019:

1 Translated by the author of this paper. 
Slađana Stamenković: Human Identity in Hyper-Reality: The Hyperreal Self in Don Delillo's...

41). Cosmopolis and The Silence represent the contemporary incarnation of each of these ideas. It could be said that these novels are, to an extent, the result of extremization of such ideas, since the effects of the media and technology are arguably much more intensified in these two novels than they are in DeLillo's earlier fiction.

\section{Baudrillard's Theories of Hyperreality and Simulacra}

Introduced and defined by French theorist Jean Baudrillard, hyperreality represents a constructed reality (Baudrillard 1994: 22). It is no longer real, objective and universal, but highly invented, generated and artificial. At the heart of such a notion lies Baudrillard's theory of simulacra and simulation, which defines a simulacrum as a basic unit of hyperreality. A simulacrum could be defined as a copy that exists without an original, or rather a copy whose "original no longer even exists" (Baudrillard 1994: 99). It is a replica that has surpassed its original referent and become completely independent by denying any connection between the two in the process. Although such ideas existed long before Baudrillard throughout history, it is Baudrillard who defines simulacra as distinctly postmodern phenomena. According to him, contemporary society has become has only gradually become more prone to confusing the real and the simulacrum. The boundaries between the real and the fictional (or fictionalized) have become more and more blurred because the imitation has become so similar to the original that the differences are almost imperceptible. In such conditions, clear borders between the real and the non-real have disappeared, since the real has become "more real than the real" (Baudrillard 1994: 81). As Noble reinterprets Baudrillard's theory, "the hyper-real transcends representation only because it is entirely in simulation" (Noble 2010: 186). The result is an unclear blend of the two, which Baudrillard describes in the following way:

It is no longer anything but operational. In fact, it is no longer really the real, because no imaginary envelops it anymore. It is a hyperreal, produced from a radiating synthesis of combinatory models in a hyperspace without atmosphere. (Baudrillard 1994: 2) 
With the loss of distinction between the simulacrum and the reality, it is plausible to discuss the loss of reality itself (i.e. Baudrillard's "real" that he proclaims lost not only in Simulacra and Simulations, but also in his other publications, such as America), as well as the loss of the idea of Self and personal identity, since the referent for its construction has become unattainable. In other words, personal identity (and thus the idea of Self) depends on the perspective of reality, given that identity is "a matter of defining the self against a given environment" (Leach 2020: 31). Without any solid basis within the real, the Self becomes evasive, insufficiently structured and grounded. Since the real has become replaced, or at least interfered with, by the nonreal, the concept of Self also acquires some of the traits of the hyperreal - the blend between the real and the simulated. Thus, society no longer has a firm reality, and is left with simulacra only personal identity included. This, of course, has not happened spontaneously or independently. Several phenomena have influenced the merger of reality and simulacra, and they are all features of postmodern society. One of them is the mass media. With the development of mass media, the connection between the "real" events and the "pseudo-events" (or simulacra of events) has gradually disappeared, because contemporary Western society has become obsessed with the image. The mass media as a means of simulation is what generates hyperreality, according to Baudrillard's observations about the quantity of information present in Western civilization (1994: 74), and what masks the fact that the real no longer exists. Although this claim might sound exaggerated, Baudrillard's suggestion here can be interpreted as a lament on the disappearance of the pure real - the real that has not been modified or upgraded by technological or media input. On a physical level, we can still discuss reality as unchanged, yet the technologically unaided perception of reality might indeed be as lost as Baudrillard suggests, especially in DeLillo's novels. The media provide their audience with information they represent as real and the audience is expected to accept it without any question or doubt. The most important aspects of such culture, which Douglas Kellner proclaims the media culture, are the entertainment factor and the phenomenon of the spectacle (Kellner 2003: 1). Baudrillard further argues that "what we have now is the disappearance of the referent - and it is in relation to this disappearance of the referent that there is a sort of omnipresence to the sign" (Baudrillard 2003: 142). In other words, since postmodernists discarded the real as a construct, all that is left are signifiers to characterize hyperreality. Those 
Slađana Stamenković: Human Identity in Hyper-Reality: The Hyperreal Self in Don Delillo's...

signifiers are the filters which participate in hyperreality's creation. Some of them are language, information and the system of its flow, the system of communications, but perhaps the most important is the media or the mass media. Baudrillard proclaims: "We are presently living with a minimum of real sociality and a maximum of simulation" (Baudrillard 1990: 155). What he is trying to say is that there is no purely real process in the world today - there is only simulation.

In "Requiem for the Media", Baudrillard determines that the main task of the media is "[t]he production of meaning, messages, and signs" (Baudrillard 1972: 279) thus raising the question of communication. As he claims, in the contemporary era there is no direct communication, there is only the simulation of it, since in our world "there is more and more information, and less and less meaning" (Baudrillard 1994: 79). According to Baudrillard, such loss of meaning is directly caused by the mass media, which is "a place of disappearance" (Baudrillard 2003: 85). Following McLuhan's principle that the medium is the only message that has remained in the postmodern era, he advocates that "[m]essages no longer have an informational role, they test and take polls, ultimately so as to control" (Baudrillard 1993: 62). In other words, the media becomes the main protagonist of the process of simulation, masking the real and hiding the fact that there is no pure realilty; there is only hyperreality created by the media. Kellner seems to support this argument by stating:

The rise of the broadcast media, especially television, is an important constituent of postmodernity for Baudrillard, along with the rapid dissemination of signs and simulacra in every realm of social and everyday life. By the late 1970s, Baudrillard was interpreting the media as key simulation machines which reproduce images, signs and codes which in turn come to constitute an autonomous realm of (hyper)reality and also to play a key role in everyday life and the obliteration of the social. This process constitutes a significant reversal of the relation between representation and reality. Previously the media were believed to mirror, reflect or represent reality, whereas now they are coming to constitute a (hyper)reality, a new media reality, 'more real than the real,' where 'the real' is subordinate to representation thus leading ultimately to a dissolving of the real. (Kellner 1989: 68) 
Kellner reintroduces Baudrillard's ideas of the hyperreal that represents a unique blend between the real and the simulated. These ideas will serve as a good basis for his Media Culture, a study of the effect television and the mass media have on the patterns of behavior in Western civilization. McHale seemingly agrees with the idea of the mass media affecting one's perception of Self and personal identity (1987). He believes that "[a] 11 around us - on advertisement hoardings, bookshelves, record covers, television screens - these miniature escape fantasies present themselves" whose incorporation (although frequently subconscious) into the very core of one's identity results in people's living "as split personalities [whose] private life is disturbed by the promise of escape routes to another reality" (McHale 1987: 38). In other words, it is the general confusion created by hyperreality that makes people reach for fictionalization. Baudrillard introduces the term "TV verité" (French for the truth) in Simulacra and Simulation and claims that "it is TV that is true, it is TV that renders true" (Baudrillard 1994: 29). When Buckingham observes different influences on the identity (one of which is media culture), he notes that "all these [contemporary] developments are contributing to a sense of fragmentation and uncertainty, in which the traditional resources for identity formation are no longer so straightforward or so easily available" (Buckingham 2007: 1 ). Hence, people turn to what is readily available in order to acquire certain and successful patterns of behavior and define themselves against the existing tradition. In DeLillo's novels, the protagonists base a large portion of their identities on what they see in the media and define themselves in relation to the society and reality which are either directly shaped or modified by the mass media.

\section{The Perception of the Self in Hyperreality of DeLillo's Novels}

The initial appearance of hyperreality in DeLillo's fiction is by no means related to either Cosmopolis or The Silence. This concept has long been present in his novels starting from the very first - Americana - which is set inside the world of television and film production, both of which can be interpreted as hyperrealities. Baudrillard's hyperreality is frequently involved in DeLillo's novels with the content created by technology or the mass media (including radio, television, film and the Internet, as well as press and advertising). Television reoccurs as the central hyperreality in 
Slađana Stamenković: Human Identity in Hyper-Reality: The Hyperreal Self in Don Delillo's...

many of his novels, most notably in White Noise, but also in Americana, Libra, Falling Man, Underworld and Players. In each novel, television seems to function as an augmentation of existing reality, adding traits to the lives of numerous protagonists, regarding their personalities or attitudes. In White Noise, Gladneys will acquire symptoms of intoxication from both television and radio broadcasts covering the toxic spillage. In Americana, David Bell will fashion himself and his manners after different movie stars. In Underworld, Nick's mother will regard the world of television as more real than the real (the episode in which she compares the animals on TV and animals in the zoo), while Nick himself will feel that people in advertising know him better than perhaps anyone else in his life. When television is not the chief operator of the hyperreal, it is some other media outlet; in Running Dog, it is newspapers, in The Names it is documentaries, in Underworld it is also the radio and the Internet (the former concerned with the baseball match, the latter with sister Edgar's obsession with tabloid websites). Technology will also contribute to the creation of hyperreality in DeLillo's novels, sometimes indirectly (as a means of media operation and functioning) and sometimes directly, like in Ratner's Star (concerning the operation of the scientific center which tries to analyze the mysterious signal detected in outer space) or Zero $K$ (concerning the institution that oversees the process of cryopreservation). The joint issue of every hyperreality is reflected in DeLillo's protagonists, each of whom struggles with their personalities and relationships with the people that surround them. All of these seem to come from the same issue seen in Cosmopolis "the disturbed relations between the past, present and future" (Paunović 2017: 186). Under the influence of the media and technology, the notions which people use to define reality become more difficult to grasp and understand, which in turn leads to a perplexed perception of the Self.

Jeremy Rifkin, studying the influence of science and technology on American society, states that "sometimes, adoption of a single technology can be transformative in nature, changing the very way our minds filter the world" (Rifkin 2004: 89). In Cosmopolis, Eric Packer adopts every single item of the latest technology as it appears. His mind is under the influence of technological wonders to the extent that he wants to "live on a disc" (DeLillo 2003: 105). He is connected to various material things in his life, not only to his gadgets but his other possessions, as well. The first scene introduces Packer as feeling strangely connected to his home the modern, high-tech building that embodies his values to a significant 
extent. As Laist puts it, "his material environment is a crucial component of his characterological makeup" (Laist 2010: 261). This contributes to the way he perceives reality, and thus himself. For him, technology is a way to foresee the future, outgo the present and triumph over it. The technology in his limousine helps him predict the events, thus allowing him to control the flow of cyber-capital. Technology is a way to work with his capital directly but by using its digital representation. It helps him be completely distant from the physicality of money, yet make it increase in his bank account. It also helps him seem distant and unaffected by the world in chaos brought by the changing conceptions of time and space, as well as of Self and reality. As Packer's antagonist in the novel Benno Levin states, Packer is "always ahead, thinking past what is new" (DeLillo 2003: 152). His ability to see into the future is more a matter of the technology available to him and to a lesser degree a matter of natural gift. Eric Packer is not a prophet; he is an analyst. DeLillo represents him as the man who has mastered technology to the level that he is able to see patterns in reality and make assumptions about the future.

As opposed to him, the protagonists of The Silence are far less obsessed with technology, or so it seems at first glance. Indeed, they do not think about it as much as Eric. They do not depend on it to the extent that he does, especially since their professions are not directly related to technology. Their connection to technology seems to be a subconscious, taken-for-granted sense that technology is a normal part of their everyday lives. They are not aware of it in normal circumstances, yet its sudden absence shocks them to the core. Jim and Tessa do not think much about their airplane on their way home to New Jersey, or the technology of screens Jim follows so obsessively on the flight. However, when the crash of communications forces their pilot to make an emergency landing), they face life-threatening destruction once technology suddenly disappears from their lives. Diane and Max (the couple whose Superbowl watch-party Jim and Tessa are about to attend) are unaware of their attachment to their television screen until it blanks, and they see themselves reflected in the blackness of the flat surface, not recognizing a functional human being that is able to have a conversation, at a minimum, without the aidance and guidance of the media content. They live their lives unaware of the isolation technology and the media inflict on their lives. However, once these elements disappear from their environment, they realize that neither they nor the rest of the society knows how to function in a community. 
In a similar way, Eric Packer is completely involved in the digital world, isolated from almost any human contact in his high-tech limousine. Not only is he separated from the outside world by the glass and chassis of his limousine, but he also does not watch the events directly through the window - he monitors them on the screen, often even before they occur. This can be seen as an echo of DeLillo's previous novels, namely the concept of media mediation that Duvall notices in White Noise and describes as "the intertextual web of prior representations" (Duvall 1994: 181). Packer does not predict the future as much as he notices patterns that he has previously noted in the media and applies them to his surroundings. Moreover, he approaches his surroundings through media mediation sometimes entirely. At one point, he comments on the riot outside the car, stating that it "makes more sense on TV" (DeLillo 2003: 89). What is striking about the limousine is the fact that from the outside, it is completely normal, even common on the streets of New York. It looks generic and resembles numerous other non-distinct limousines that sail the streets of New York. It almost echoes William Gibson in No Maps for These Territories (2000), a documentary in which the author travels in a similarly technologically super-equipped limousine while discussing several dystopian points and potential scenarios we also see in Cosmopolis; namely, the influence of technology on the future of our civilization. Interestingly, both authors have ominous expectations of the future world. Much like Gibson's, Eric's limousine completely blends into the environment on the outside. However, on the inside, it is highly equipped, enabling Packer to constantly monitor the flow of information, equally concerning the economy and the media. It is a surreal machine, "less an object than an idea" (DeLillo 2003: 10). With its flat plasma screens and surveillance systems it becomes his whole world - it replaces the office, the bar, the place where he can meet his mistresses. This way it forms a hybrid environment, a surreal and hyperreal cell that traps him inside the world of never-stopping data. He himself is fascinated by this world, mesmerized by the information and completely enchanted by "the hell-bent sprint of numbers and symbols, the fractions, decimals, stylized dollar signs, the streaming release of words, of multinational news, all too fleet to be absorbed" (DeLillo 2003: 80). However, he fails to recognize that these signs are all there is - they are just the image of reality with no real value in it, other than the abstract value we ascribe to it. The digital representation of capital is a signifier, Baudrillard's simulacrum - an arbitrary construct which might as well be empty of any meaning. 
This is why Eric works with cyber-capital; on a metaphorical level, DeLillo involves him with a simulacrum and not real, palpable money to highlight the lack of connection between the real world and the image that only claims to be real.

The lesson that escapes Eric is painfully learned by the protagonists of The Silence. Faced with the total absence of technology, they ponder upon the meaning and purpose of human existence. Once screens go blank, and while waiting hopefully and somewhat naively for their reignition, Diane contemplates "the many millions of blank screens" and tries to imagine "the disabled phones" (DeLillo 2020: 52). Waiting for their friends, her husband Max and Diane somehow manage to retain the structure of their day still revolving around the media and technology. They are suddenly left without them, but they stay within their bubble, as much as Eric Packer does. They wait for the screens to start broadcasting the game of the Superbowl and keep preparing for the event as if it is still going to happen. They never leave the seat in front of the screen empty, "waiting for something to splash onto the screen" (DeLillo 2020: 84). If we compare the two novels, the ominous silence that fills their apartment only highlights the isolation embodied by all the functional screens in Cosmopolis. Nevertheless, Diane spares a moment or two to timidly think about the possibility of the screens' never functioning again. Then, she poses a question that might as well be directly related to Eric Packer: "What happens to people who live inside their phones?" (DeLillo 2020: 52). In other words, she voices DeLillo's concern with the society that functions highly (or even entirely) relying on technology. The suggested answer is - silence.

A similarly sharp and philosophical character in Cosmopolis, Vija Kinski is absorbed in information and in the world of statistics and she states that they "are not witnessing the flow of information so much as pure spectacle, or information made sacred, ritually unreadable" (DeLillo 2003: 80). She is much more aware of the true nature of this spectacle, and she often analyzes the media and contemporary society in a similar fashion Murray Siskind does in White Noise, for example. They are both able to perceive the deeper level of media messages and sense some profound meaning and influence on the audience. However, while the author seems to be exceedingly ironic in representing Siskind's observations about the true nature of media messages, his approach to Vija Kinski is less ironic and more critical, since her observations are less related to conspiracies and more to the socio-cultural implications of a media-led society. She allows 
Slađana Stamenković: Human Identity in Hyper-Reality: The Hyperreal Self in Don Delillo's...

herself to contemplate and discuss the possibility of future destruction (and the potential disappearance of technology), though she does not seem able to surpass the environment she inhabits - she is, like Eric, stuck in the simulation of the world. While other employees that Eric meets throughout the day mention hints of their lives outside their work within Eric's hyperreality, Vija seems to exist solely within philosophy and theory. Moreover, her relationship with Eric never crosses the level of discussion (about hyperreality almost exclusively) and she remains unable to offer a glimpse of anything real (in terms of activities unpolluted by the hyperreal, such as the hairdresser's story, the taser Eric's bodyguard uses on him or Danko's narration of the war he was previously in). Vija and Eric remain the only two characters who do not offer anything authentic beyond the hyperreal, either in activity or experience. However, the difference between the two of them (and between Eric and the protagonists of The Silence) is that he seemingly feels comfortable in the simulation of the contemporary era. He is no more than a data processor - more an object than a man, since his body and the real world are of secondary meaning to him, a "meat space" as he keeps calling it throughout the novel. Moreover, he is equally surreal to the people around him. For example, Didi has to put her hand on Eric's chest to "determine he was here and real" (DeLillo 2003: 25). To his wife Elise, he is almost a stranger; she is baffled by some of his physical traits (his eyes, for example), unsure of his likes and dislikes, and sometimes even fails to recognize him physically when she encounters him in unexpected settings outside their home. Furthermore, Eric cannot seem to grasp the identity of the people around him either. He contemplates "putting his sunglasses on the associate's [doctor Ingram's] face, to make him real" (DeLillo 2003: 53) since "[i]t is what people think they see in another person that makes [their] reality" (DeLillo 2003: 57). He cannot recognize Elise any better than she can recognize him and knows her even less than she knows him; she is just a wife with whom he is yet to consummate their marriage. It is quite obvious that Eric is not aware of what is real, even though he insists that he does not live "an unreal life" (DeLillo 2003: 58). He is aware of the fluidity of the new reality but experiences it completely indirectly. For example, despite being aware that he is at a film location, he contemplates: "It tore his mind apart, trying to see them here and real, independent of the image on a screen in Oslo or Caracas. Or were those places indistinguishable from this one?" (DeLillo 2003: 176). At this point, we can again observe the resonance that White 
Noise has in this novel; namely, the similarity between Eric's observation about the movie set and the phenomenon of the most photographed barn in the US from White Noise, whose merit does not lie in its appearance or historical significance, but rather in its being a media spectacle. The scene in Cosmopolis occurs while Eric simulates stiff bodies with his wife on a movie set - a hyperreality of its own.

For Eric, the actual reality, the world in the streets, is what offends the "truth of the future" (DeLillo 2003: 65). However, as a practical man he is, he still needs human contact, much like Benno for whom "there are times when [he wants] to rub [himself] against a door or wall, for the sympathetic contact" (DeLillo 2003: 58). Both in fact yearn for any sort of true and real connection with other people. This is precisely why Eric insists on knowing Benno's real name or having sex with his wife on the movie set. In fact, when it comes to movies, it is a common saying among people that something in real life is "just like in the movies" and Eric embodies this idea. For example, before bursting through the door of Benno's apartment he thinks about what characters in the movies do when they burst in through the door, kicking the thing only once and it always flies open at the first attempt. He enacts the action, proving that the action has the same result in both reality and fiction, further proving the premise that the two are the same thing. In a similar way, Martin states that "[o]ne escape is the movies" (DeLillo 2020: 51) when he discusses the strategy to avoid facing one's confusion about the Self. In this manner, the hyperreality of the movies takes dominance over authentic reality in DeLillo's protagonists' perspective.

Like Eric, Benno Levin (or Richard Sheets, which is his real name) has a distorted perception of reality. His reality is highly subjective, an example of a postmodern merger of facts and fiction, reality and imagination. For example, he convinces himself that he is suffering from diseases and conditions that he found and caught online, because he read about their symptoms, much like the Gladneys children in White Noise. He is convinced that things are real just because he believes in them. He says: "Whether I imagine a thing or not, it's real to me. I have syndromes where they're real, from Malaysia for example. The things I imagine become facts. They have the time and space of facts" (DeLillo 2003: 213). Eric will scorn Benno's intention to kill him, describing it as a "cheap imitation" (DeLillo 2003: 213) because it is something that the world has already seen. "Do people still shoot at presidents?" Eric asks (DeLillo 2003: 20). By doing this, Eric 
Slađana Stamenković: Human Identity in Hyper-Reality: The Hyperreal Self in Don Delillo's...

degrades every experience that is not original, ironically ascribing more importance to the real than to the fictional. However, it is questionable whether anything can be truly original in the world that has seen it all from the media. As previously discussed in the chapter on Baudrillard's hyperreality, society no longer functions on the unmediated real. Therefore, any comparison with the pure real is ungrounded and needlessly exclusive in DeLillo's novels.

In The Silence, DeLillo's protagonists are faced with similar identity issues. Yet, their approach is much less self-assured than Eric's. For example, he would never ask himself whether he is "being a little too selfimportant" (DeLillo 2020: 102). Eric is too immersed in the world of the media and technology; his attention is elsewhere, and he has no time for self-inspection. As opposed to him, Max, Diane, Tessa, Jim and Martin have nothing but time and space which are respectively to be filled with introspection and their newfound awareness of their humanity, or lack thereof. They are reduced to their most immediate physiological functions (sleeping, eating, breathing) and - conversing with the people surrounding them. For example, once Jim and Tessa crash-land and survive their violent arrival home, they conclude that "[t] here was nothing for them to do but to keep walking" (DeLillo 2020: 63). However, these, otherwise completely normal, activities of human lives become increasingly difficult for them. As they spend time without technology and the media, they become highly introspective. Each of them withdraws deep within, to the point at which they stop noticing each other. On several different occasions, Diane has to remind herself to pay attention to her surroundings. "It began to occur to Diane that Martin was speaking, although not necessarily to her," the narrator notes (DeLillo 2020: 50). What DeLillo seems to imply here is that the sudden switch, which brings the characters back to their basic daily operations and activities, does not manage to switch off the bubble previously created by the media - the one that, in his novels (mainly and most notably Underworld) keeps people deeply connected with the media content, but distant from other human beings. With such unexpected upset, their normal activities become exaggerated. For instance, they talk to themselves, like Martin, for the sake of talking. They sleep excessively and yearn for sleep when they pretend to be fully awake like Jim and Tessa, whose tiredness does not seem to come solely from their accident but also from the overwhelming new reality they find themselves in. They become obsessed with their appearance, like Martin who cannot stop discussing 
(out loud, yet for himself) how he looks at himself in the mirror, yet does not recognize the man he encounters in that reflective surface. Without technology and the media, they seem lost.

The reason for this is, DeLillo seems to suggest, that people rely on technology and the media to tell them what is real and how to behave. The examples such as Jane Melman in Cosmopolis, who prefers face-toface communication, rather than consulting one of Eric's many screens for information, are rare and even perceived as strange, out of touch with the real world merely for the fact that they are actually out of touch with the hyperreality they inhabit. Moreover, they all constantly seem to perform. It is as if they have acquired the type of behavior they see on television and in the movies and try to incorporate it into their quotidian, making thus another level of hyperreality. As Benno Levin puts it, in the contemporary world "it's hard not to lie" (DeLillo 2003: 150) suggesting that they all pretend to some extent. They all seem to be reduced to roles; it is just a question of how obvious they are in performing them. An example of how much role-play is present in the hyperreal world of these two novels is seen in Benno Levin, who is acquiring the role of his victim Eric. He starts talking like him, even thinking like him. He is similar to Walter White from Breaking Bad for example, who also picks up the habits of his victims (concerning the sandwich crust, the towel etc.) or even more so of Nabokov's Hermann from Despair who also tries to morph into another man - Felix. This might be interpreted as representation of human identity as a construct since Benno is shedding one and adopting another as if it is a piece of clothing. If we compare the novels, this only seems to be highlighted by the bareness of character that the protagonists of The Silence exhibit. None of them performs their roles like Benno or Eric because they are uncertain of what they are supposed to imitate now that they no longer have a referent in the media world. Yet, DeLillo does not represent them as completely authentic or purely real, either. They may have been stripped off the media referent for behavior, but there are still remnants of performance practices acquired from the media. For example, while talking to Martin, Max does not talk, he "announces" (DeLillo 2020: 51). Martin himself seems to be an echo of an actor performing a play, although his musings about Self and life in general resemble more a coping mechanism, an action one performs to distract oneself from the horrors of reality. Furthermore, traces of performances can be seen in the scene when Max decides to go outside and see what other people are doing to cope 
Slađana Stamenković: Human Identity in Hyper-Reality: The Hyperreal Self in Don Delillo's...

with the new situation, and Diane "almost feels obligated to sit in front of the TV set on his behalf" because that is how one is expected to behave on a Superbowl Sunday - she overtakes his role of a spectator (DeLillo 2020: 84). Their actions are infused with fear and confusion, but the patterns exhibited in them are still quite media-affected.

In Cosmopolis, similarly, everything people do is "for effect," as Eric puts it when he takes off his sunglasses to have a conversation with his wife. He has quite a few metanarrative moments, almost all of which take place while he communicates with his wife, showing exactly how even their marriage is a performance. Participating in a conversation is a performance, as well - he notices that he is noticing, that he is complimenting, he is literally uttering every part of the social behavior that is expected and that he performs. The only thing that seems to "strip them of appearance" and performance is sex, or at least they perceive it as such. "Sex finds us out. Sex sees through us. That's why it's so shattering. It strips us of appearances" Eric states (DeLillo 2003: 50). He finds it to be the only way to reality. However, even that premise is questionable. Sex seems to be a pure simulation in the novel, as well. The most obvious example is the experience that Eric and Jane share, when they do not even touch each other, they only simulate. Moreover, Eric and Elise have their first marital sex on the movie set, highlighting the fact that they just perform their marital roles. Sadly, this proves that even such an intimate level of one's personal life is not spared of the effect of the popular media, since all of them seem to reenact something they have previously seen represented by media culture.

There do not seem to be any aspects of life left that the media has not affected somehow. They create a media image of everything (such as a perfect man, a TV spectator, an action hero), and it is by rule always perfect and beautiful, an ideal people should strive for, whether it concerns physical looks or possessions or actions. This is probably why Eric is so bothered by the asymmetry of his prostate - it is not picture perfect like the media shows it ought to be, like everything ought to be. Inevitably, the world that is so obsessed with appearances is doomed to fail, because no matter how much it tries to be resemblant of what the media represent as the ideal, it will never succeed at achieving that ideal, mainly because it is a pure simulation, a thing that is almost completely disconnected from the actual life. "The future is always a wholeness, a sameness. We're all tall and happy there,' Vija says. 'This is why the future fails. It always 
fails. It can never be the cruel happy place we want to make it"' (DeLillo 2003: 91). Her comments might be DeLillo's ironic observation about the society that regards the future as the land of fairytales. Nevertheless, people still try to reach it, the chief reason being that, like the "glow of cyber-capital," it is also so "radiant and seductive" (DeLillo 2003: 78). It is precisely seduction that is another important element that the media incorporates in the making of spectacles. It is the aura of exoticism that lures people to watch something, just because it is new. For this reason, the reporters repeat the word dacha in Cosmopolis and the protagonists of The Silence stubbornly wait for the Superbowl to start, even though no piece of technology functions in their surroundings - the audience is always lured by the spectacle in DeLillo's novels.

\section{The Concept of Disappearance}

In order to return the balance to the world, Vija Kinski states that there must be some destruction, that something needs to be destroyed to stop the world from rushing into the future. This occurs as she perceives a huge discrepancy between past and present ways of life. In Cosmopolis, destruction will symbolically be embodied in Eric Packer's death. Similarly, the world in The Silence has to experience a unique technological catastrophe or the destruction of technology and mass media. Eric can be interpreted as a representative of the contemporary American society and a symbol, a "third Twin Tower," as Laist calls him (Laist 2010: 257). The Twin Towers stood as symbols of an economic ideology, and so does Eric Packer ${ }^{2}$. He is deeply defined by the ideology of contemporary society. In a similar way, Max, Diane and others are also symbols of the ideology, only from a different angle - they are what the ideology can and will leave behind. Eric seems to run into destruction almost willingly, as he pursues potentially dangerous activities and areas. He lives the day aware of the constant threat and gets reports of various potential assassins multiple times. However, he does not seem to mind - on the contrary, he seems to long for it. The characters of The Silence are not as self-hazardous as he is, indeed, yet that might

2 It should be stated that Cosmopolis is set in 2000, and there are no explicit references to 9/11 in the novel. Therefore, the symbolism of the Twin Towers as mentioned in this paper is entirely related to the time before their destruction, when they represented American economic supremacy and their monetary power. 
Slađana Stamenković: Human Identity in Hyper-Reality: The Hyperreal Self in Don Delillo's...

only be due to the initial shock of losing solid ground of familiar reality. They are left with no technology and are represented in a state of initial confusion after a catastrophe, whereas Eric has become an integral part of the digital world and currently lives its apex. Laist notes that Eric is "completely fused with technology" (Laist 2010: 259). As a result of such oversaturation, he feels the need to exist outside it, even though he is unaware of it. For this reason, he wants to get his haircut in his childhood neighborhood; he is on a quest for some real, authentic experience outside the hyperreal. Symbolically, he unconsciously leads himself to the financial "haircut" and death, as well. On the other hand, Diane and her friends are forced into stupefaction by the circumstances (the sudden, but total, disappearance of functioning media and technology). Nevertheless, the protagonists of these novels are quite similar. Eric is a man who does not experience reality directly anymore, much like the protagonists from The Silence - his sexual encounters, his medical examination - he seems above it all, existing as a supervisor of his own life. He cannot even experience his own death - he foresees it on a screen. Diane, Max, Martin and the rest do not command technology openly, but once they are left without it, they find themselves incapable of leading a technology-free life. They act as if the whole world has been destroyed when the failure only extended to technology-based practices. In both novels, technology has completely alienated all DeLillo's protagonists from nature and culture, but from people as well. In addition to technology and language, interpersonal relationships constantly become obsolete, as well. Packer does not need human interaction - he cannot even tell if he is alive without the data from his medical results. That is why he does not recognize his wife whenever she appears. That is why she does not know his eyes are blue. Regarding The Silence, it is for this reason Diane and Max cannot communicate openly with each other or with others, especially Martin. Their media experience dominates human interaction, which is why they wait desperately for the broadcast to reappear instead of doing something together. As DeLillo says in Cosmopolis, technology "can go either way" (DeLillo 2003: 95) - to the future or to the ruin of it. What is only hinted at in Cosmopolis, occurs in The Silence. The future and the ruin were always meant to be synonymous. 


\section{Conclusion}

As in other DeLillo's novels, in Cosmopolis and The Silence, we encounter one of the crucial topics of contemporary society: the never-ending hyperreality present in every aspect of life. The society as DeLillo represents it in his novels has come to the point where technology is defining human lives and existence. As Vija Kinski says, "The present is harder to find. It is being sucked out of the world to make room for the future of uncontrolled markets and huge investment potential" (DeLillo 2003: 79). In Cosmopolis and The Silence, the characters experience hyperreality in a similar, yet strikingly different manners. These novels could not be farther removed on the spectrum of DeLillo's novels regarding the level at which hyperreality operates. The former is the noise, the latter the noiselessness; the former is the peak of technological dominance, the latter its utter failure. In Cosmopolis, the omnipresence of technology and the media directly dictates the lives of Eric Packer and the rest of DeLillo's protagonists. In The Silence, the utter absence of these elements indirectly highlights the level of importance technology and the mass media play in the protagonists' lives. Under the influence of these elements, the shifted perception of the world that DeLillo's protagonists experience is reflected in their identity issues. DeLillo's dystopian America of these two novels directly results in his characters' becoming lost, unsure of themselves and always on a never-ending quest for something real in their lives. All protagonists exhibit complete and unconditional reliance on technology; Eric Packer's abundant use of technology is parallel to the desperate yearning for the reestablishing of the media and technology experienced by the protagonists in The Silence. The issues of human identity and perception of Self, as well as of what it means to be human in a hyper-technological dystopia of DeLillo's America, are suggested to be under an unerasable influence of the hyperreal, one that cannot be diminished even by a total removal of the media content and technology. In such a state, DeLillo's protagonists are left to seek authentic experiences deeply unaware of the fact that they no longer have the ability to truly experience them on a direct, technologyfree level. 
Slađana Stamenković: Human Identity in Hyper-Reality: The Hyperreal Self in Don Delillo's...

\section{References}

Baudrillard, J. (1972). Requiem for the Media. In: Van Hulle, D. (ed.) (2005). The New Media Reader. Variants: the Journal of the European Society for Textual Scholarship, (4), 278-288. (30 September 2021) $<$ http://shmacek.faculty.noctrl.edu/Courses/MediaCritSyllabusSPR2 files/19-baudrillard-03.pdf $>$.

Baudrillard, J. (1990). Seduction. New York: St. Martin's.

Baudrillard, J. (1993). Symbolic Exchange and Death. London: Sage Publications.

Baudrillard, J. (1994). Simulacra and Simulation. Ann Arbor: University of Michigan.

Baudrillard, J. (2003). Baudrillard Live: Selected Interviews. (ed.) M. Gane. London: Routledge.

Buckingham, D. (2007). Youth, Identity, and Digital Media. MIT Press.

DeLillo, D. (2003). Cosmopolis. New York: Scribner.

DeLillo, D. (2020). The Silence. New York: Symon and Schuster.

Duvall, J. N. (1994). The (Super) Marketplace of Images: Television as Unmediated Mediation in DeLillo's White Noise. Arizona Quarterly: A Journal of American Literature, Culture, and Theory, 50(3), 127-153.

Duvall, J. N. (2008). The Cambridge Companion to Don DeLillo. Cambridge University Press.

Kellner, D. (1989). Jean Baudrillard: From Marxism to Postmodernism and beyond. Stanford, CA: Stanford.

Kellner, D. (2003). Media Spectacle. London: Routledge.

Laist, R. (2010). The Concept of Disappearance in Don DeLillo's Cosmopolis. Critique, 51.3, 257-275.

Leach, N. (2020). Topophilia/Topophobia: The Role of the Environment in the Formation of Identity. In: X. Ruan and P. Hogben (eds.), Topophilia and Topophobia, London: Routledge, 31-43.

McHale, B. (1987). Postmodernist Fiction. London: Routledge.

Neale, M. (Director). (2000). No Maps for These Territories [Film]. Docurama.

Noble, S. (2010). Don DeLillo and Society's Reorientation to Time and Space: An Interpretation of Cosmopolis. Critique, 51.3, 257-275.

Paunović, Z. (2017). Prozor u dvorište. Beograd: Geopoetika.

Rifkin, J. (2004). The European Dream: How Europe's Vision of the Future Is Quietly Eclipsing the American Dream. New York: Penguin. 
Stojmenović, V. (2019). Representations of Dailiness in Don Delillo's Novels. Kultura, (162), 40-58.

Received: 10 October 2021

Accepted for publication: 19 November 2021 